\title{
Salvage endoscopic ultrasound-guided stent placement into a stent that had migrated into the peritoneum during a hepaticogastrostomy procedure
}

Hepaticogastrostomy has become a standard procedure for biliary obstruction when endoscopic retrograde cholangiopancreatography (ERCP) is not feasible. Nevertheless, it remains challenging and stent migration into the peritoneum is a well-known complication, occurring in $2.7 \%$ of cases [ 1 ], and possibly leading to death [2].

Different salvage techniques have been reported to pull the stent back into the stomach using either a cholangioscope through the gastric hole [3] or natural orifice transluminal endoscopic surgery $[4,5]$.

We report the case of a 78-year-old woman with a pancreatic cystic adenocarcinoma initially invading the duodenum. Duodenal obstruction was treated by surgical gastroenterostomy. One month later, the patient was referred for biliary drainage under endoscopic ultrasound guidance by hepaticogastrostomy because ERCP was impossible.

After puncturing the left bile duct with a 19-gauge needle and an 8.5-Fr cystotome, a dedicated $8-\mathrm{cm}$, half-covered self-expandable metal stent (SEMS; Hanarostent; Life Partners Europe, Bagnolet, France) was introduced into the left liver. The stent was accidentally deployed too fast and migrated into the peritoneal cavity outside the stomach. We failed to catch the stent with forceps through the gastric hole. We used EUS to detect the stent in the peritoneal cavity ( $\mathbf{F i g . 1}$, - Video 1) and then punctured the stent lumen with the 19-gauge needle for guidewire placement within the stent. The guidewire was pushed into the common bile duct and an 8-cm covered SEMS was placed to make a bridge between the migrated stent and the gastric lumen ( Fig.2). Fluoroscopic control with contrast revealed no leakage and the patient did not experience peritonitis during follow-up.


- Fig. 1 Hepaticogastrostomy for duodenal obstruction by a cystic adenocarcinoma. a Left bile duct dilation on computed tomography. $\mathbf{b}$ Migrated stent within the peritoneal cavity (red arrow shows the migrated stent in the peritoneum). c Puncture of the stent with a 19-gauge needle (red arrow shows the migrated stent within the peritoneum; yellow arrow shows the 19-gauge needle for puncture). $\mathbf{d}$ Cystotome recanalization after guidewire placement into the stent.

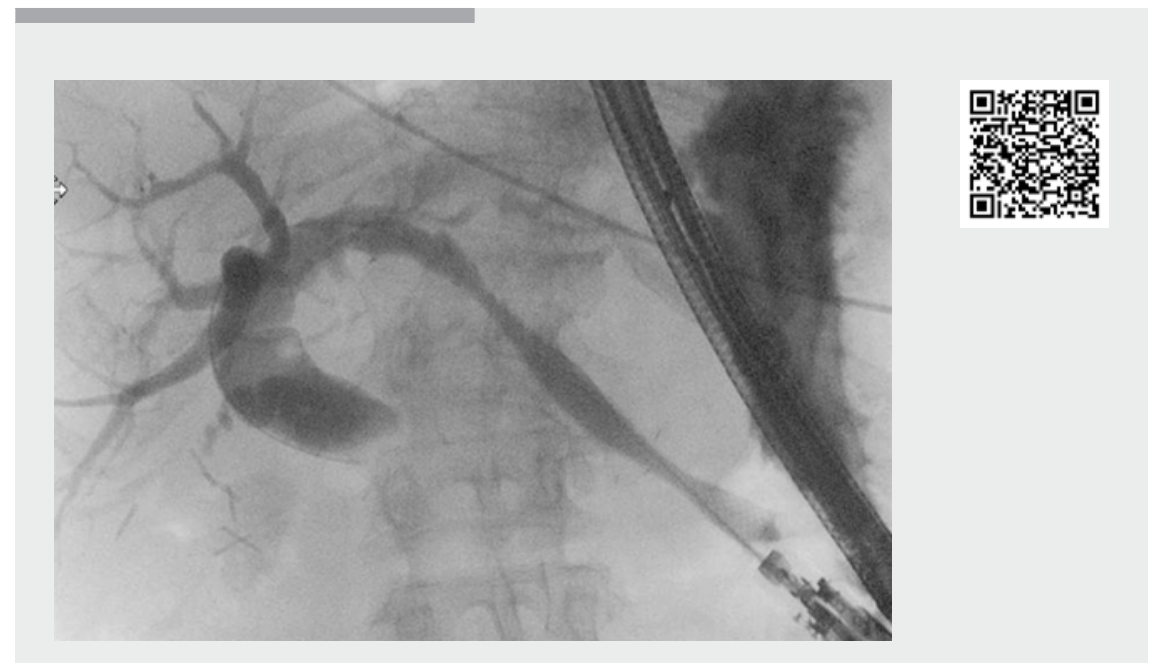

$\checkmark$ Video 1 Salvage endoscopic ultrasound-guided puncture and stent placement into a self-expandable metal stent that had migrated into the peritoneum during a hepaticogastrostomy procedure. 

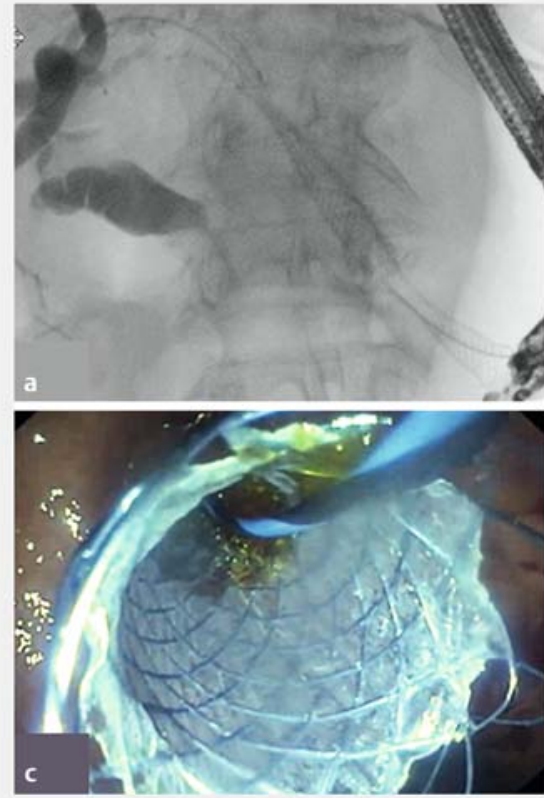

- Fig. 2 Second stent placement into the migrated stent to make a bridge between the left bile duct and the stomach. a Stent deployment into the migrated stent. $\mathbf{b}$ Confirmation of no leakage. c Second stent opening and bile drainage into the stomach. d Fluoroscopic control.

Peritoneal migration of the stent during hepaticogastrostomy is a highly stressful adverse event. Without changing the scope, EUS puncture to place a guidewire and to introduce an SEMS into the migrated stent can save the procedure to achieve the hepaticogastrostomy without leakage.

Endoscopy_UCTN_Code_CPL_1AL_2AD

\section{Competing interests}

The authors declare that they have no conflict of interest.

\section{The authors}

Miruna Cruceru ${ }^{1}$, Marianna Milashka ${ }^{1}$, Florian Rostain ${ }^{1}$, Mickaël Mochet ${ }^{1}$, Maxime Delvincourt ${ }^{1}$, Jérémie Jacques ${ }^{2}$, Mathieu Pioche $^{2,3}$

1 Department of Endoscopy and Gastroenterology, Edouard Herriot Hospital, Lyon, France
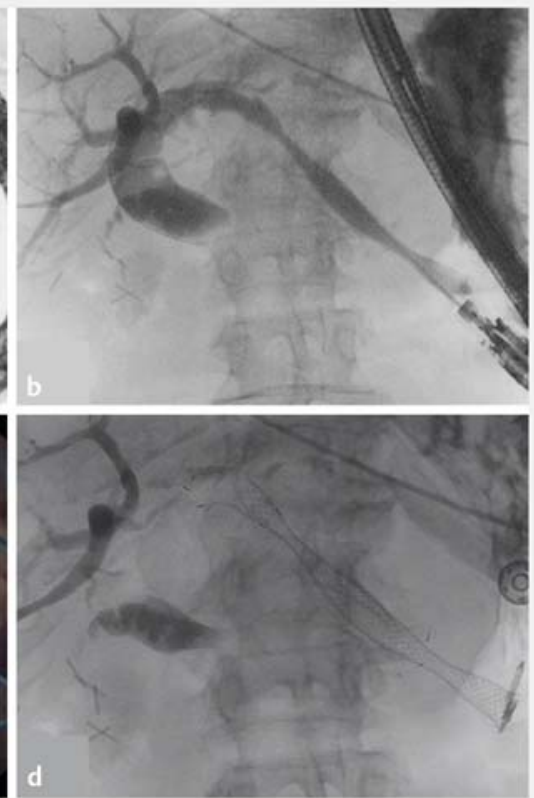

[3] Saito T, Hamada T, Kogure H et al. Digital cholangioscopy-guided retrieval of a migrated hepaticogastrostomy stent through a created hepaticogastrostomy route. Endoscopy 2020. doi:10.1055/a-1119-0987

[4] Pham KD-C, Hoem D, Horn A et al. Salvage of a dislodged hepaticogastrostomy stent in the peritoneum with NOTES. Endoscopy 2017; 49: 919-920

[5] De Moura DTH, Mestieri LHM, Cheng $S$ et al. Natural orifice transluminal endoscopic surgery to salvage a migrated stent during EUSguided hepaticogastrostomy. Gastrointest Endosc 2016; 83: 656-657

Bibliography

Endoscopy 2021; 53: E69-E70

DOI 10.1055/a-1193-4359

ISSN 0013-726X

published online 19.7.2020

(c) 2020. Thieme. All rights reserved.

Georg Thieme Verlag KG, Rüdigerstraße 14,

70469 Stuttgart, Germany

\section{ENDOSCOPY E-VIDEOS}

https://eref.thieme.de/e-videos

Department of Endoscopy and Gastroenterology, Dupuytren Hospital, Limoges, France

3 INSERM U1032, LabTau, Lyon, France

\section{Corresponding author}

\section{Mathieu Pioche, MD}

Endoscopy Unit, Digestive Disease Department, Pavillon L - Edouard Herriot Hospital, 69437 Lyon Cedex, France Fax: +33-4-72110147

mathieu.pioche@chu-lyon.fr

\section{References}

[1] Wang K, Zhu J, Xing L et al. Assessment of efficacy and safety of EUS-guided biliary drainage: a systematic review. Gastrointest Endosc 2016; 83: 1218-1227

[2] Martins FP, Rossini LG, Ferrari AP. Migration of a covered metallic stent following endoscopic ultrasound-guided hepaticogastrostomy: fatal complication. Endoscopy 2010; 42: $126-127$ 